\title{
A resistivity cross-section of Usu volcano, Hokkaido, Japan, by audiomagnetotelluric soundings
}

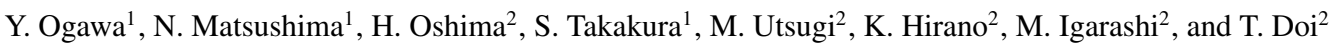 \\ ${ }^{1}$ Geological Survey of Japan, 1-1-3 Higashi, Tsukuba, Ibaraki 305-8567, Japan \\ ${ }^{2}$ Department of Earth and Planetary Sciences, Hokkaido University, Sapporo, Hokkaido 060-0810, Japan
}

(Received April 11, 1997; Revised March 12, 1998; Accepted March 17, 1998)

\begin{abstract}
We collected audio-magnetotelluric (AMT) data across Usu volcano, Hokkaido, Japan, which erupted in 1977 and is still active. We had a profile of 17 sites perpendicular to the regional tectonic strike, which crossed the 1977 cryptodome, Usu-Shinzan. Tensor-decomposed data were interpreted by a two-dimensional inversion. Outside the crater rim, the resistivity structure is simple. The resistive somma lava is underlain by a conductive substratum, implying altered Tertiary or Quaternary rocks. In the crater, there are two resistive bodies bisected by a vertical conductor, which corresponds to Usu-Shinzan fault, located at the foot of the uplift. The vertical conductor was not detected in the AMT sounding in 1985. One of the possible causes of the development of the vertical conductor is a cold water supply from the surface into the vapor dominant fracture zone. One of the resistive bodies is located beneath Usu-Shinzan and implies an intrusive magma body which caused the 1977 uplift.
\end{abstract}

\section{Introduction}

Usu volcano is located in the southern Hokkaido (Fig. 1). The outer cone of the volcano was created by andesitic magma activity ten thousand years ago (Soya et al., 1981). It became inactive for the subsequent several thousand years, but became active again in 1663. Since then, the historic records show periodic (30-60 years) eruptions. The recent eruption took place in 1977 and 1978 after 32 years of dormancy. Associated with the 1977-1978 eruption, cryptodomes, Usu-Shinzan (US) and Ogariyama (OG), were created in the center of the summit crater (Fig. 1). They were characterized by viscous dacite magma and formed a ridge in the SE-NW direction. The uplift amounts to $180 \mathrm{~m}$ and its southwestern edge is fringed by a sharp cliff and a fault called Usu-Shinzan fault (USF in Fig. 1, Katsui et al., 1985).

Intensive geophysical studies have been carried out after the eruption. Ground temperature mapping at $1 \mathrm{~m}$ depth showed that high temperature region $\left(80^{\circ} \mathrm{C}\right)$ spread in the southwestern half of the summit crater. Nishida and Tomiyama (1987) found a positive self-potential (SP) anomaly, corresponding to the high temperature. They interpreted the SP as an electro-kinetic effect between porous rock matrix and fluid. These SP anomalies imply that the southwestern crater is an upflow region of geothermal water. Repeated SP surveys have shown a decrease in the amplitude with time, however, its wavelength stayed the same (Matsushima et al., 1990). This means that the size of the hydrothermal system is maintained although the geothermal activity is declining.

In order to understand the volcanic system, it is essential to study the subsurface structure by geophysical techniques, such as seismological and electrical methods. Be-

Copy right $(\mathcal{C}$ The Society of Geomagnetism and Earth, Planetary and Space Sciences (SGEPSS); The Seismological Society of Japan; The Volcanological Society of Japan; The Geodetic Society of Japan; The Japanese Society for Planetary Sciences. neath the uplift, there was an earthquake-free zone, which was interpreted as magma at high temperature (Okada et al., 1981). Watanabe et al. (1984) qualitatively interpreted a compiled pseudo-section of dipole-dipole resistivity data and suggested an existence of low resistivity anomaly beneath the uplift, implying a magmatic melt. Scalar AMT soundings $(1700 \mathrm{~Hz}$ to $8 \mathrm{~Hz}$ ) were done by Ballestracci and Nishida (1987) in the crater. They found increasing resistivity toward Usu-Shinzan fault and interpreted it as representing a vapor zone. Recently, Nishida et al. (1996) attempted imaging the resistivity structure across Usu volcano. Their frequency range is wide but is very sparse. It is covered by three kinds of narrow-band MT equipments $(17.4 \mathrm{kHz}$, $8-20 \mathrm{~Hz}$, and $0.008-0.05 \mathrm{~Hz}$ ). Their resistivity modeling is based on a stitched one-dimensional inversion using the effective impedances, i.e., arithmetic averages of the two principal impedances. They showed that the volcano is underlain by a conductor, top of which shallows toward the center of the crater. They interpreted it as representing a geothermal water-bearing layer.

The objective of this study is to show the initial twodimensional inversion results of our AMT surveying using spatially dense sites and continuously wide band tensor data. From the modeling, we will show a cross-section of the volcano to a depth of $\approx 500 \mathrm{~m}$. Our special interest lies in the imaging of the 1977 uplift.

\section{Data Presentation}

Figure 1 shows the locations of our 17 AMT sites. They are located both inside and outside of the crater rim. We used a tensor AMT system manufactured by Phoenix Geophysics Ltd. The frequency range was from $10,000 \mathrm{~Hz}$ to $1 \mathrm{~Hz}$. We measured two horizontal magnetic fields and two horizontal electric fields. There were no vertical magnetic field measurements. The typical dipole length was $50 \mathrm{~m}$. We 


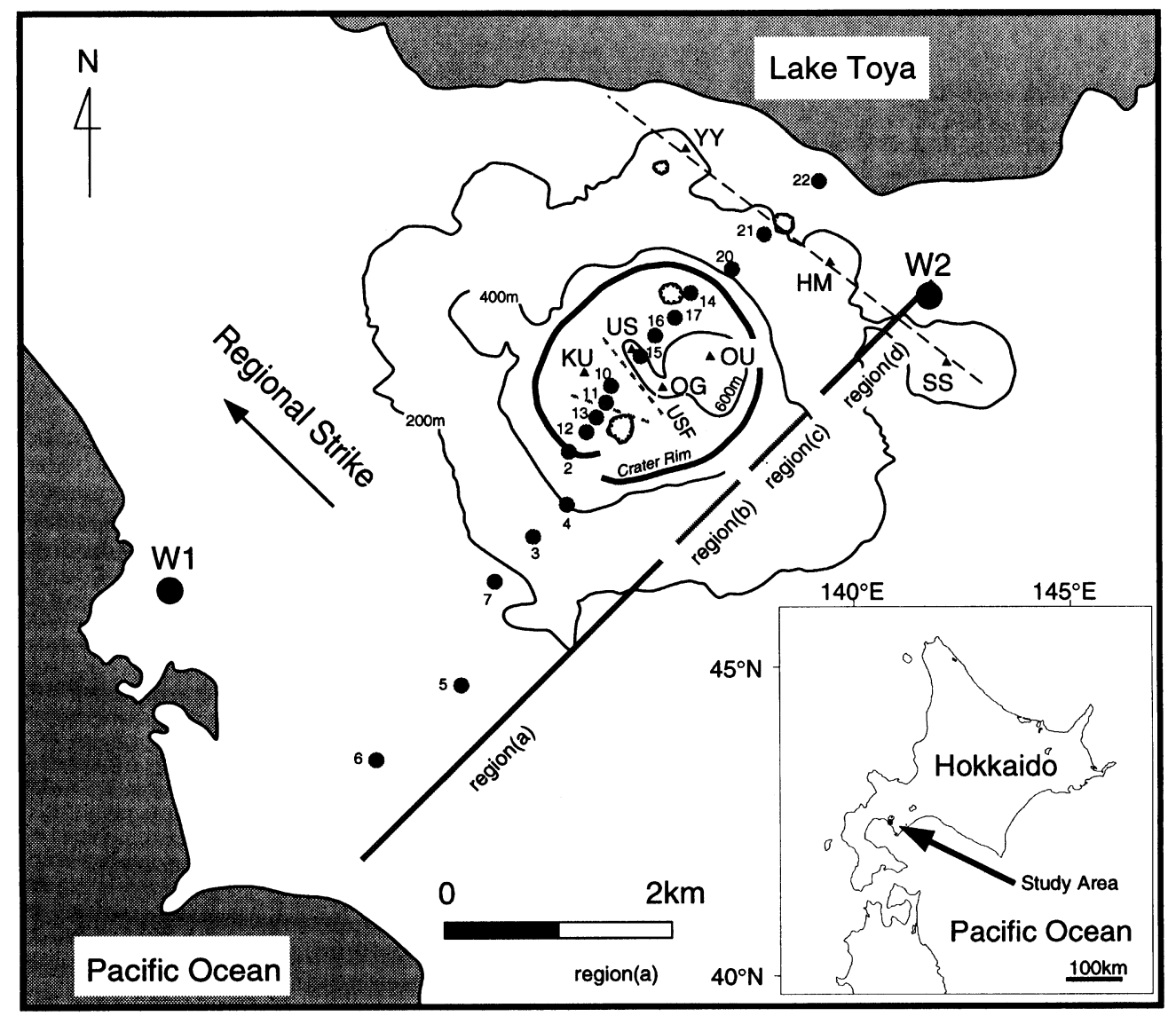

Fig. 1. Location of Usu volcano (inset) and the distribution of audiomagnetotelluric sites. KU, OU, and SS denote lava domes Ko-Usu, O-Usu, and Showa-Shinzan. US, OG, YY, and HM denote cryptodomes Usu-Shinzan, Ogari-yama, Yosomi-yama, and Higashi-Maruyama. The broken line over YY, HM, and SS denotes a line of domes. USF indicated by a grey broken line denotes Usu-Shinzan fault. W1 and W2 are drill holes to a depth of $1200 \mathrm{~m}$. Regions (a)-(d) are subdivisions of the profile for the strike study.

spent $2-10$ hours at each site. Some soundings were done overnight.

Usu volcano is located at the southwestern margin of the Toya volcano, whose caldera is now seen as Lake Toya (Fig. 1). The distributions of the domes around Usu volcano as well as the 1977 uplift are aligned in the NW-SE directions (Fig. 1). These geological evidences imply a regional twodimensional structure with NW-SE strike directions. We assume a two-dimensional regional resistivity structure, overlain by three-dimensional local heterogeneities.

To confirm this approximation, we carried out tensor decompositions (Groom and Bailey, 1989). First, we investigated if there is a regional strike direction. The impedance data were decomposed site by site and frequency by frequency. Figure 2 show the histograms of the estimated strikes. Note that $\pi / 2$ ambiguity is taken into account. The left four columns (Fig. 2(a)-(d)) show rose diagrams for each period band for the four different groups of sites in Fig. 1. Figure 2(a) shows diagrams for the sites in the region (a), outside the crater. The strikes are almost consistent in the NW directions over the four decade of frequencies. Figure 2(b) shows diagrams for the region (b), southern half of the crater, which is geothermally active. The roses show almost consistent strikes in W to WNW directions. Figure 2(c) shows diagrams for the region (c), the northern half of the sites inside the crater. The diagrams are more scattered in the lower frequencies, but there is a predominance in the NW direction. Figure 2(d) shows diagrams for the region (d), the northeastern sites outside the crater. We can find a consistent direction (NW) throughout the frequencies. The rightmost column shows the summed histogram for all the sites. The NW direction is predominant in the $10-100 \mathrm{~Hz}$ band. The scattering of the estimated strikes is due to the local preferences of strike directions. Especially, the region (b) has a unique preference. As seen in Fig. 1, there are faults in W-WNW directions in the southern half of the crater. Thus, the preference in the W-WNW may be reflecting fractured zones at depth.

As a first-order approximation we decided to choose NW direction for a regional strike in our subsequent modelings. After fixing the strike direction to NW, we decomposed all the impedance data, using site-dependent and frequencyindependent twist and shear. The static shifts were handled later as part of a two-dimensional inversion.

Figures 3(a) and (b) show pseudosections of the decomposed impedance phase for TM and TE modes, respectively. First we point out the common features in both modes. Sites southwest of the crater (sites 6, 5, 7, 3, 4) are characterized by high phase $\left(>60^{\circ}\right)$ for both modes from the high frequencies. This reflects a sharp resistivity contrast between a 


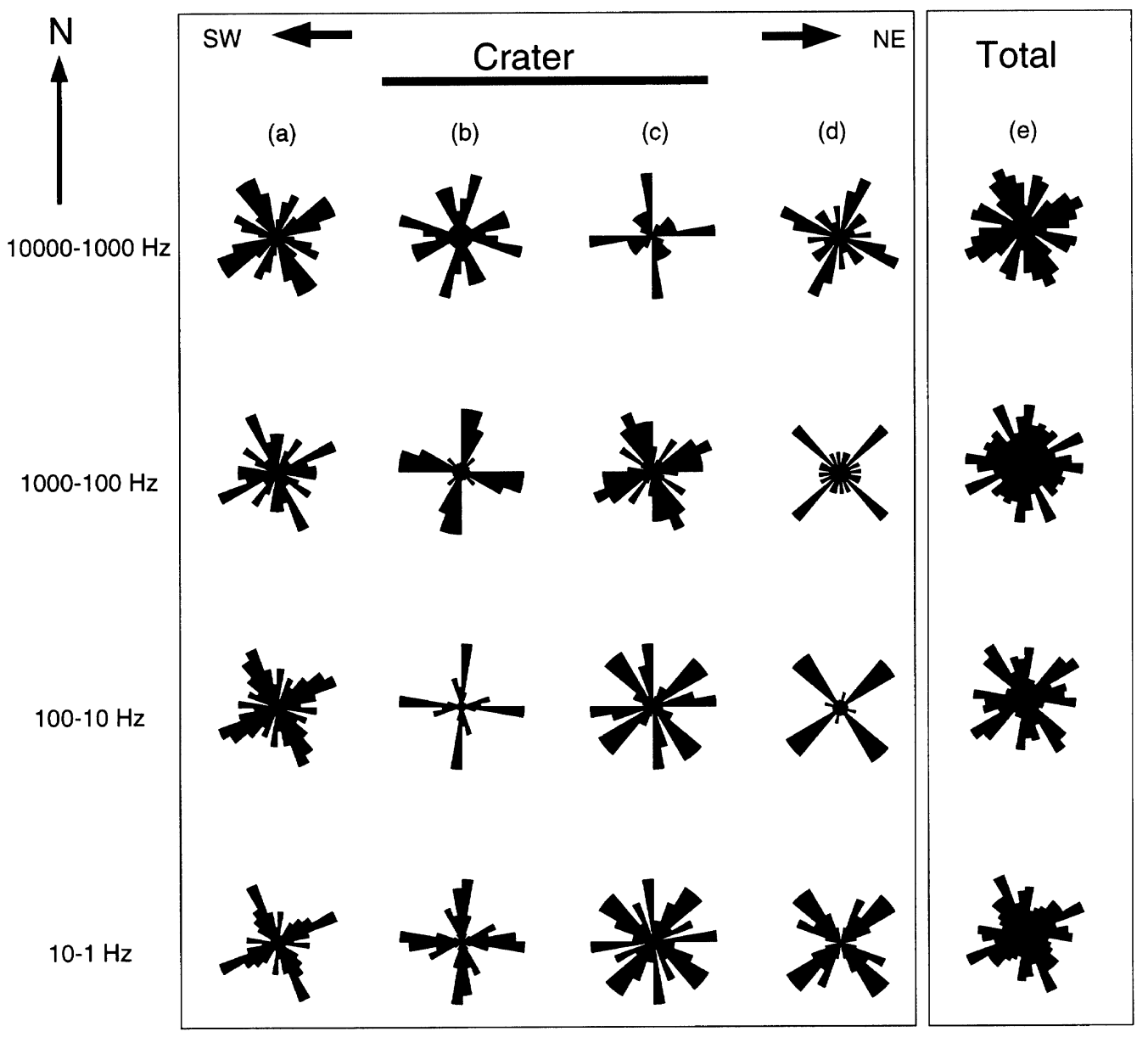

Fig. 2. Rose diagrams of the estimated strikes after decomposition. Each row and column represent a decade of frequencies and a geographical region. For each rose, upper direction denotes north. The size of the rose is normalized. The $\pi / 2$ ambiguity is also shown. (a) southwestern sites outside the crater, (b) southwestern sites inside the crater, (c) northeastern sites inside the crater, (d) northeastern sites outside the crater, and (e) all the sites.

surface resistive layer and underlying conductive substratum. A similar feature is also seen at northeastern sites outside of the crater rim (sites 20, 21, 22), where the high phase deepens toward the crater. On the other hand, inside the crater the high phase is lost and the difference between TM and TE phase is significant. In TM mode (Fig. 3(a)), we can trace the high phase over $1000 \mathrm{~Hz}$ from site 15 to site 14 . There is no corresponding TE high phase. The TE mode, however, has a SW-deepening high phase anomaly at the southwestern edge of the crater (site 2 to site 10). Another significant difference in two modes exists at the northeastern edge of the survey line (site 22), where we found a low TM phase anomaly between 100 and $1000 \mathrm{~Hz}$. This implies an emergence of a different structure to the northeast.

The apparent resistivity pseudosections are shown for both modes (Fig. 3(c), (d)). As shown later, the apparent resistivity and phase are consistent for each site. However, the observed apparent resistivity can be affected by static shift.

\section{Two-Dimensional Modeling}

The features of the data described above are reflected in the model. We used a two-dimensional inversion code of Ogawa and Uchida (1996). The algorithm imposes two constraints. One is the roughness of the resistivity model and the other is the static shift $L_{2}$ norm. We had a concern about the sharp cliff of Usu-Shinzan, which has a comparative scale to the exploration depth of this study. The explicit correction for topography was not applied, but the topography was included in the model. The initial model was a uniform earth of $100 \Omega \cdot \mathrm{m}$ resistivity with no static shifts. We had an error floor of $10 \%$ for apparent resistivity data, i.e., the data with less than $10 \%$ error were forced to have error of $10 \%$. An equivalent error floor was used for phase data. After 20 iterations the rms (root mean square of the misfit) converged to 1.68 . This means that the model explained the data with $16.8 \%$ error, because we had $10 \%$ error floor. Figure 4 shows representative data with model curves. We confirmed that the major features of the dataset are reproduced by the model calculations. Figure 5(a) shows the static shift estimates. The static shift varies within one decade. We do not see clear relations between the topography and the amount of static shifts. We note, however, the two sites have significantly large static shift: site 2 on the southwestern crater rim and site 10 at the foot of the 1977 uplift (Usu-Shinzan). Figure 5(b) shows the final model resistivity. 

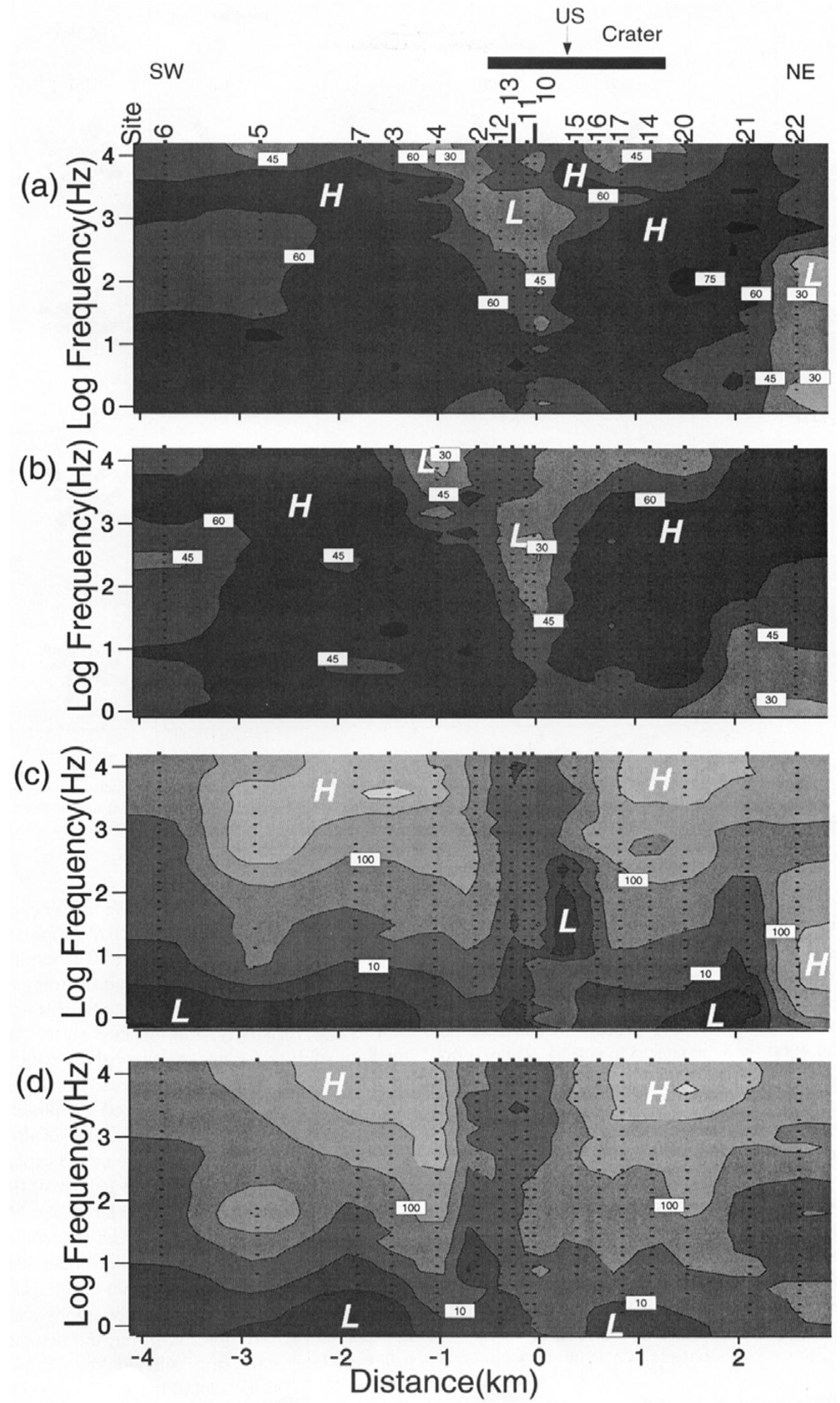

Fig. 3. Pseudo-sections for decomposed impedances: (a) impedance phase in TM mode, (b) impedance phase in TE mode, (c) apparent resistivity in TM mode, and (d) apparent resistivity in TE mode. 

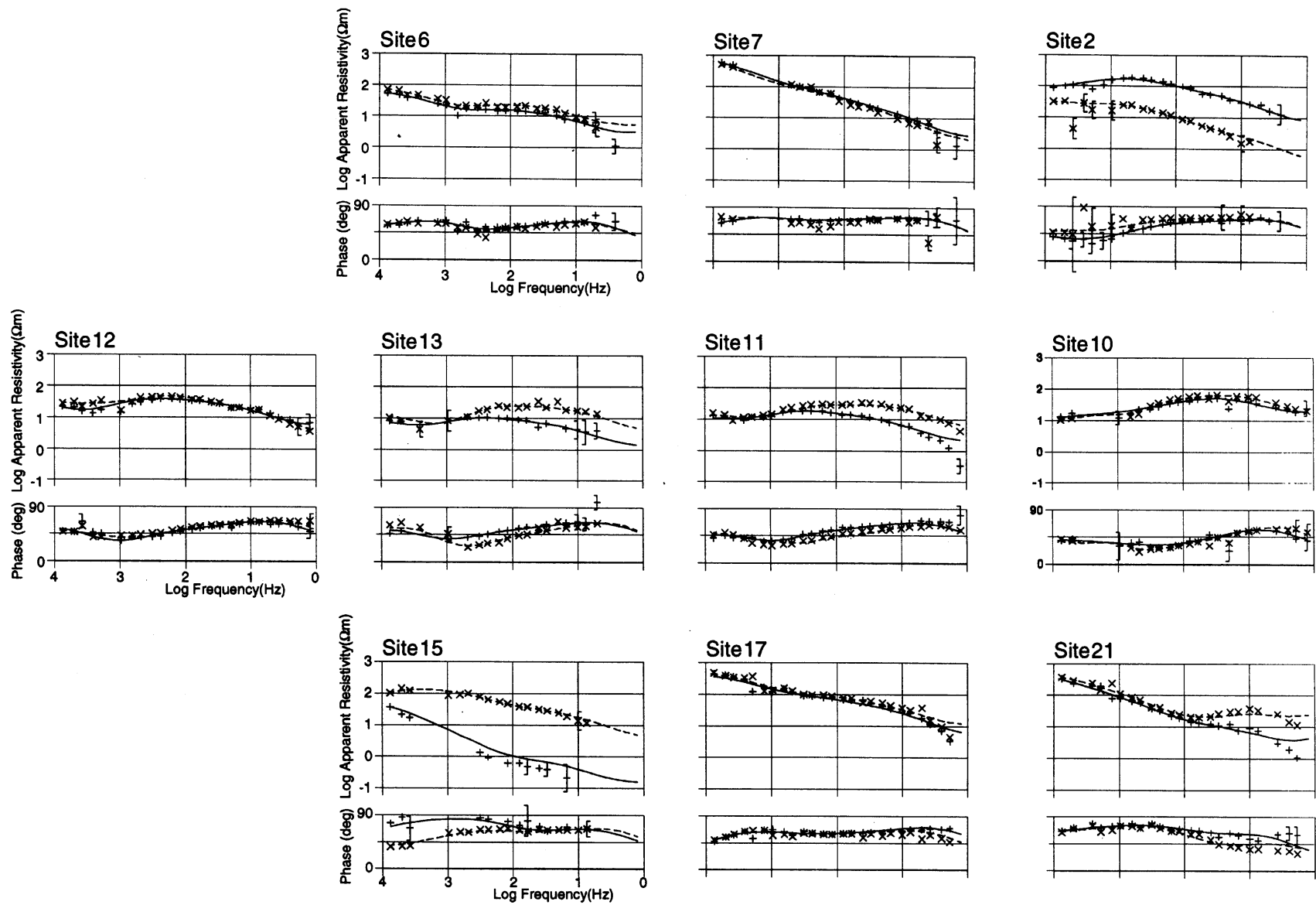

Fig. 4. Typical sounding curves from west to east. The + and $\times$ denote observed values of TM and TE mode respectively. The model curves are also drawn. Solid and broken lines denote TM and TE mode respectively.

\section{Discussion}

The simplified resistivity model is illustrated in Fig. 5(c). Surface resistive layers outside the crater on both sides imply the basaltic somma lava. These resistors correspond to layers with the strong magnetization inferred from a detailed magnetic survey (Nishida and Miyajima, 1984). Over the whole area, we had a conductive substratum, which becomes less significant beneath the crater. Nishida et al. (1996) interpreted this conductor as a layer containing geothermal fluid.

Matsushima and Oshima (in preparation) compiled electrical logging data around the volcano (W1 and W2 in Fig. 1). The locations of these wells were projected on to the profile. Wells W1 and W2 encountered Tertiary sedimentary rocks (Muroran formation) and Tertiary volcanic rocks (Soshunaigawa formation), respectively. From the electrical loggings of both wells, the Tertiary layers showed low resistivity (less than $10 \Omega \cdot \mathrm{m}$ ). In Fig. 5(c), top of the Tertiary conductor is represented by a thick line, beneath the wells (W1 and W2). These electrical loggings are consistent with the model. The low resistivity is due to the clay (smectite) alteration and the conductor itself is not a porous layer but an impermeable layer, which can cap the underlying geothermal systems (Matsushima and Oshima, in preparation).

Toward the crater, the conductive substratum becomes higher in altitude. There are no drillings which hit the Ter- tiary layer in the crater region. Thus we cannot simply interpret the conductor as the extension of the Tertiary conductive layer found by drilling in the foot of the volcano. However, there is an exposure of the Tertiary rocks at the foot of KoUsu lava dome (KU in Fig. 1), which was brought up to the surface at the time of the uplift of Ko-Usu (Yokoyama et al., 1973; Soya et al., 1981). This suggests a shallow Tertiary layer beneath the crater region (Yokoyama et al., 1973). Between Usu-Shinzan fault and Usu-Shinzan, the conductive substratum is not significant. The relatively resistive substratum beneath the crater implies intrusion of magma into the Tertiary layers.

There is a geothermal manifestation in the northeastern part of the profile (Sobetsu hot spring). We have a corresponding conductor at the surface underlain by a resistive layer. According to the well logging data (W2), the surface conductive layer and underlying resistive layer imply altered Quaternary volcanic layer and Quaternary welded tuff. The southwestern edge of the tuff corresponds to a line of domes in Fig. 1. Thus we infer that the uplift of domes took place utilizing the structural boundary as a mechanically weak zone.

The southwestern half of the crater shows a surface $(<100 \mathrm{~m})$ conductive layer $(\mathrm{C} 1)$, underlain by more resistive bodies (R1 and R2). C1 implies volcanic deposits composed of pumice and ash (Soya et al., 1981). It extends underneath 
(a)
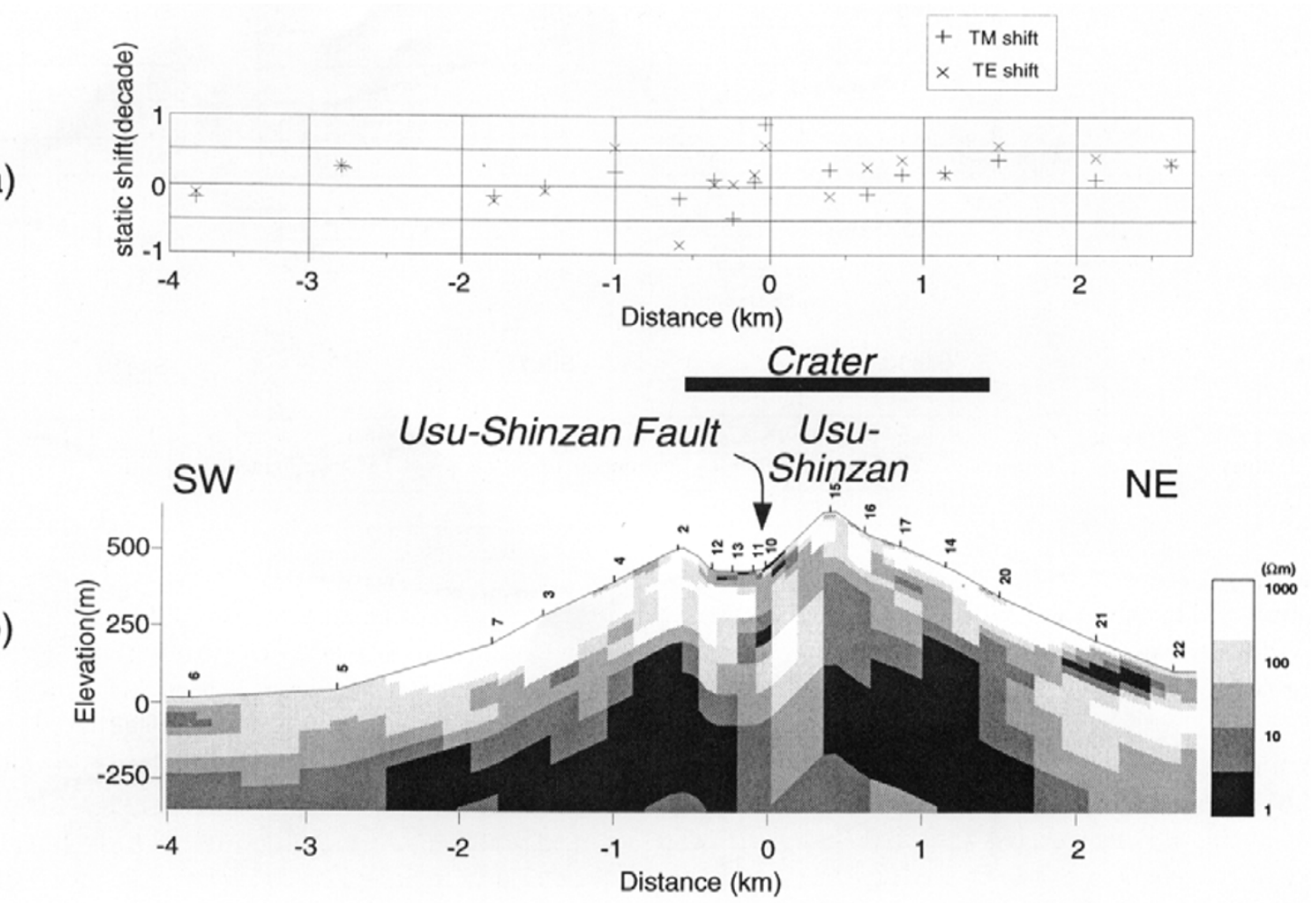

(b)

Crater

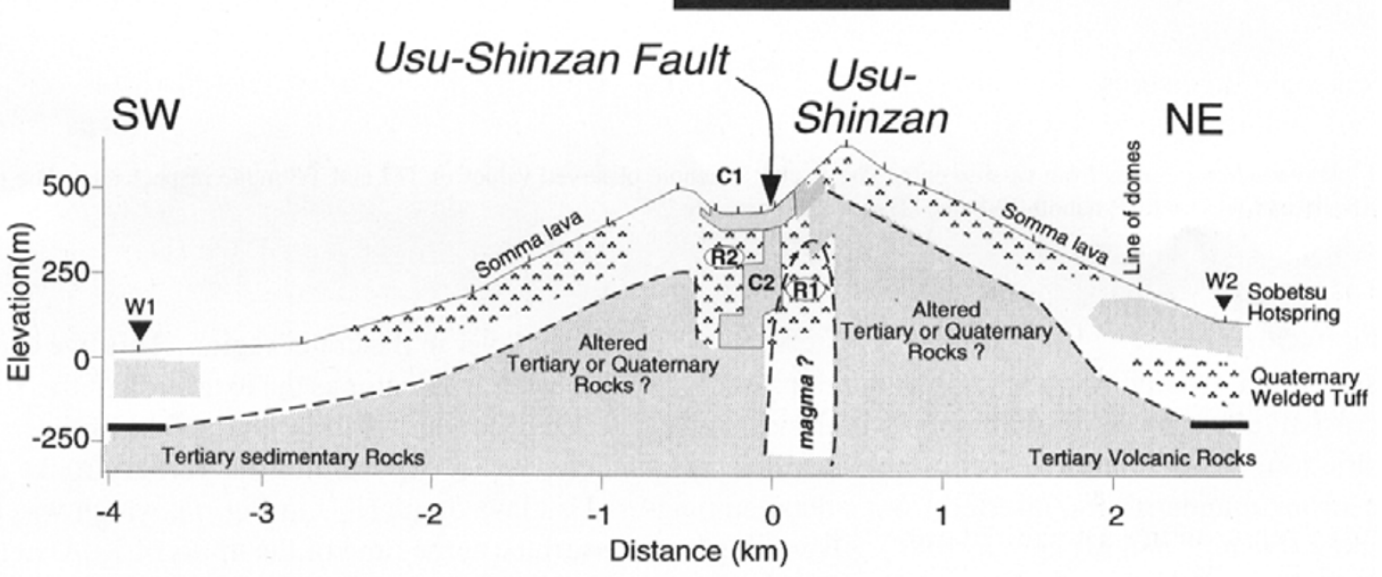

(d)

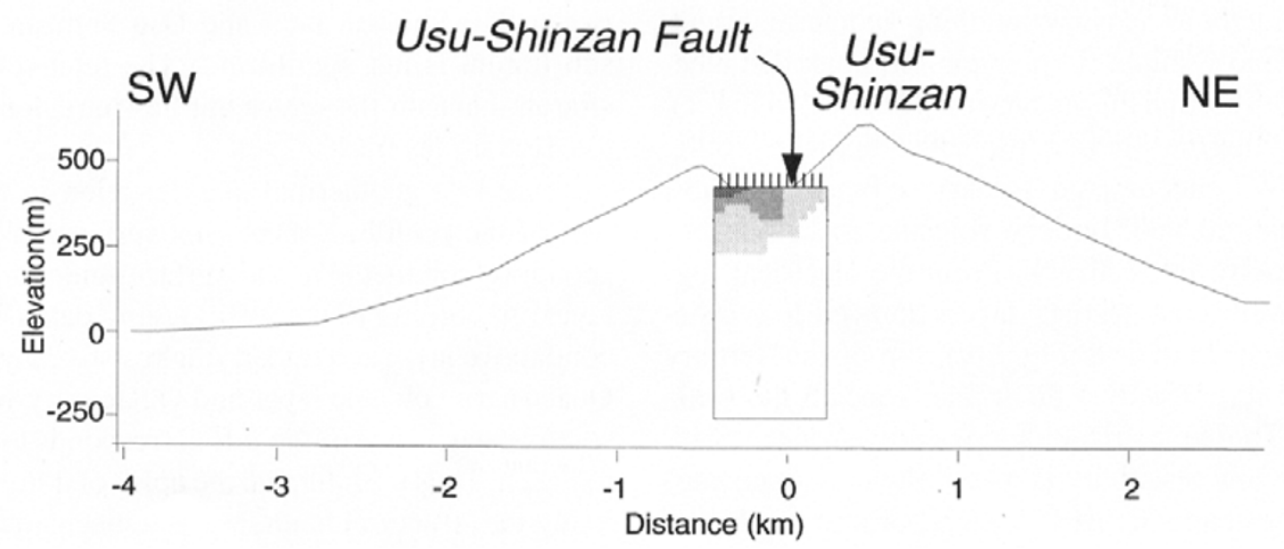

Fig. 5. (a) Distribution of static shifts. (b) Final resistivity model with vertical exaggeration 2:1. (c) Simplified final resistivity model. R and C denote resistive and conductive bodies, respectively. (d) Re-interpreted model from the 1985 AMT data of Ballestracci and Nishida (1987). 


\section{Test model}
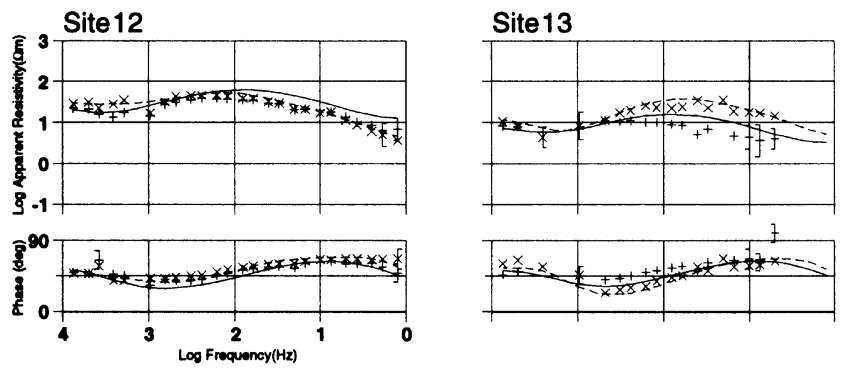

Site 11
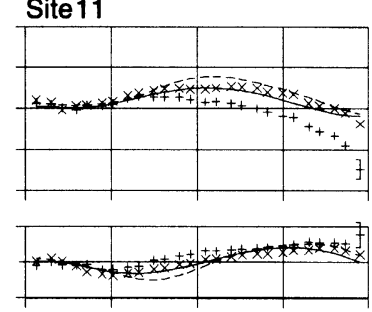

Site 10

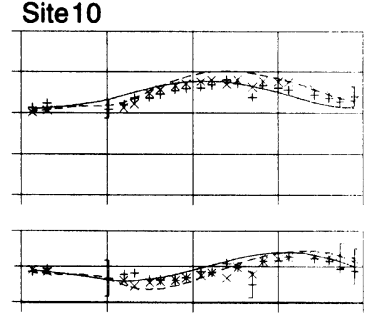

Fig. 6. Apparent resistivity and phase responses from the test model, where $\mathrm{C} 2$ conductor in Fig. $5(\mathrm{c})$ is replaced by $300 \Omega \cdot \mathrm{m}$. The + and $\times$ denote observed values of TM and TE mode respectively. Solid and broken lines denote model curves of TM and TE mode, respectively.

Usu-Shinzan and is connected to the substratum conductor. Corresponding to Usu-Shinzan fault, we found a sub-vertical conductor (C2), which bisects the resistive bodies (R1 and R2).

Inside the crater, Ballestracci and Nishida (1987) conducted AMT measurements in 1985 in the frequency range 8-3708 Hz using a scalar analogue system. They showed apparent resistivity increase toward Usu-Shinzan fault in the southwestern crater. They interpreted the resistive zone as a vapor dominant zone. Their scalar data correspond to TM mode data in our modeling. We re-investigated their data by two-dimensional inversions. The inverted model is shown in Fig. 5(d). We confirmed that their data require a surface conductor underlain by a resistive layer which shallows toward Usu-Shinzan. Note here that their data do not require any vertical conductors, corresponding to $\mathrm{C} 2$ in Fig. 5(c).

The sensitivity of $\mathrm{C} 2$ in Fig. 5(c) was tested. As for a test model, we replaced $\mathrm{C} 2$ by $300 \Omega \cdot \mathrm{m}$. Figure 6 shows the test results of the sites in the southern crater, which are sensitive to C2. Without the conductor, there are significant misfits at these sites, especially below $100 \mathrm{~Hz}$ in the TM mode at sites 13 and 11, which are above the $\mathrm{C} 2$. We interpret this conductor as representing a fractured zone associated with the uplift of Usu-Shinzan. R1 and R2 represent volcanic intrusive rocks with low porosity. Here we interpret the C2 conductor was developed with time. Since the SP anomaly as well as the volcanic activity is declining, one of the possible causes is a supply of cold water into the fractured zone, which turned a vapor-dominant resistive zone into a wet conductive zone.

Oshima (1979) analyzed gravity changes around UsuShinzan during uplift and inferred a top of the magma body beneath Usu-Shinzan. The location of R1 is consistent with the top of the intrusion. We thus infer that the R1 implies the head of the intrusive magma of 1977-1978. Similar speculation leads to R2 as another intrusive magma at another time.

\section{Conclusion}

We analyzed new AMT dataset obtained in 1996 across Usu volcano. After decomposition and two-dimensional inversion, we constructed a resistivity model across the volcano. Outside the crater, the resistive somma lava is underlain by a conductive substratum. At the foot of the volcano, the substratum conductor is consistent with the altered Tertiary rocks found in the well logging data. Towards the crater, the substratum becomes high in altitude. This does not necessarily mean the extension of the Tertiary layer into the crater region, but also may imply Quaternary volcanic rocks, which are altered due to the geothermal activity. Shallow Tertiary layer in the crater region is supported by an exposure of Tertiary rocks in the crater around the Ko-Usu lava dome. In the crater, there are two resistive bodies bisected by a conductive dyke. The dyke corresponds to Usu-Shinzan fault, which was created associated with the uplift of Usu-Shinzan. The vertical conductor was not detected in the AMT soundings in 1985. One of the possible causes of the development of the vertical conductor is a meteoric water supply from the surface into the dry vapor dominant fracture zone. One of the resistive bodies is located beneath Usu-Shinzan and implies an intrusive magma body. Repeated resistivity measurements of the active volcano will give useful information on the change of activity with time.

Acknowledgments. We thank Usu volcanic observatory, Hokkaido University for assistance in the field work. We thank Tatsunori Soya and Yasunori Nishida for discussions. Critical and constructive reviews by Tohru Mogi and Pierre-Andre Schnegg improved the manuscript.

\section{References}

Ballestracci, R. and Y. Nishida, Fracturing associated with the 1977-1978 eruption of Usu volcano, north Japan, as revealed by geophysical measurements, J. Volcano. Geotherm. Res., 94, 1913-1925, 1987.

Groom, R. W. and R. C. Bailey, Decomposition of magnetotelluric impedance tensor in the presence of local three-dimensional galvanic distortion, J. Geophys. Res., 94, 1913-1925, 1989.

Katsui, Y., H. Komuro, and T. Uda, Development of faults and growth of Usu-Shinzan cryptodome in 1977-1978 at Usu volcano, North Japan, Jour. Fac. Sci., Hokkaido Univ., Ser. IV, 21, 339-362, 1985.

Matsushima, N., M. Michiwaki, N. Okazaki, R. Ichikawa, A. Takagi, Y. Nishida, and H. Y. Mori, Self-potential studies in volcanic areas (2)—Usu, Hokkaido-Komagatake and Me-akan, Jour. Fac. Sci., Hokkaido Univ., Ser. VII (Geophysics), 8, 456-477, 1990.

Nishida, Y. and E. Miyajima, Subsurface structure of Usu volcano, Japan, as revealed by detailed magnetic survey, J. Volcano. Geotherm. Res., 22, 271-285, 1984.

Nishida, Y. and H. Tomiyama, Self-potential studies in volcanic areas (1) Usu volcano-, Jour. Fac. Sci., Hokkaido Univ., Ser. VII (Geophysics), 8, 173-190, 1987.

Nishida, Y., M. Utsugi, H. Oshima, T. Kagiyama, T. Inoue, Y. Morita, S. 
Shigehara, N. Matsushima, and T. Maekawa, Resistivity structure of Usu volcano as revealed by the magnetotelluric measurements, Geophysical Bulletin of Hokkaido University, 59, 151-162, 1996 (in Japanese).

Ogawa, Y. and T. Uchida, A two-dimensional magnetotelluric inversion assuming Gaussian static shift, Geophys. J. Int., 126, 69-76, 1996.

Okada, Hm., H. Watanabe, and I. Yokoyama, Seismological significance of the 1977-1978 eruptions and the magma intrusion process of Usu volcano, Hokkaido, J. Volcano. Geotherm. Res., 9, 311-334, 1981.

Oshima, H., Gravity change associated with volcanic activity-Usu volcano, M.Sc. Thesis, Hokkaido University, 1979 (in Japanese).

Soya, T., Y. Katsui, K. Niida, and K. Sakai, Geological map of Usu volcano, in Geological Map of Volcanoes 2, Geological Survey of Japan, 1981.
Watanabe, H., H. Yamashita, and T. Maekawa, Electrical study of the 19771982 activity of Usu volcano, Geophysical Bulletin of Hokkaido University, 43, 31-40, 1984 (in Japanese).

Yokoyama, I., Y. Katsui, Y. Oba, and S. Ehara, Usu-zan, its volcanic geology, history of eruption, present state of activity, and prevention of disaster, Committee for Prevention of Disasters of Hokkaido, Sapporo, 1973 (in Japanese).

Y. Ogawa (e-mail: oga@gsj.go.jp), N. Matsushima, H. Oshima, S. Takakura, M. Utsugi, K. Hirano, M. Igarashi, and T. Doi 